\title{
THE MECHANISM OF ANAESTHESIA: A NEW HYPOTHESIS BASED ON THE EFFECTS ON ELECTRICAL PROPERTIES OF A MODEL MEMBRANE: PRELIMINARY STUDIES
}

\author{
G.A. Volgyes!
}

TWO BASIC QUESTIONS that still lack satisfactory answers are where and how anaesthetic agents exert their effects. Investigation of the first has yielded equally persuasive contrary experimental evidence from two main groups of investigators, one favouring the lipid portion and the other the protein portion of nerve membranes as the primary site of the anaesthetic action. Even more confusing are the multifarious theories of how anaesthetics exert their effects: these are now so numerous that a comprehensive review of the subject would be a major undertaking.

This preliminary study sought to identify the site and mechanism of anaesthetic action by investigating the effects of anaesthetic agents on primary electrical properties in a membrane model. A major obstacle to investigating the excitability and narcosis of nerve membranes in vivo is the interdependence of a large number of variables; for example, studies of cell-membrane conductance in vivo have shown this either decreased $^{1}$ or increased ${ }^{2}$ by anaesthesia, depending upon the experimental conditions. Therefore, a simple model was devised in which all but the variable being investigated could be kept constant. Furthermore, unlike other artificial lipidmembrane models, ${ }^{3-7}$ its size, shape and structural strength are neither limited by nor dependent upon the properties of lipid molecules within it. This model thus makes possible the investigation of a whole range of substances which may control or affect the passage of information within the central nervous system.

\section{TheORETICAL Considerations}

The electrical properties of a cell membrane can be characterized by a parallel combination of a capacitance and a resistance. The capacitance property permits storage of large amounts of potential energy; some of this is liberated during the action potential. The membrane is not a perfect insulator, so the stored potential energy tends to

Mr. G.A. Volgyesi, P.Eng., Research Technologist, Department of Anaesthesia. The Hospital for Sick Children, 555 University Avenue, Toronto, Ont., M5G $1 \times 8$.

Canad. Anaesth. Soc. J., vol. 25, no. 3, May 1978 leak away; this leakage relates to the membrane conductance. To maintain the energy store at a constant level requires its continuous replenishment.

As shown in Figure 1, the capacitance of two parallel conductive plates of area $A$ separated by a distance (d) is given by $k \epsilon A / d$, where $\epsilon$ is the dielectric constant of the material between the plates. When a substance is placed in an electric field such as that between two charged conductive plates, the permanent and induced dipoles tend to align themselves with the electric field. This weakens the electric field inside the substance by an amount that depends on the dielectric constant of that substance.

The potential energy stored in a charged capacitor arises from the force of mutual attraction of opposite charges across the insulation between the plates. Thus any change in the dielectric constant of the material between the plates affects the potential energy stored in the capacitor. If the dielectric constant increases, the forces of attraction between opposite charges decrease and the potential energy of the system diminishes.

Dielectric strength is the highest electric field that allows maintenance of the molecular structure of a substance when it is applied to that substance. An electric field that exceeds the dielectric strength of the substance causes a breakdown in molecular structure which may or may not be reversible by removal of the field.

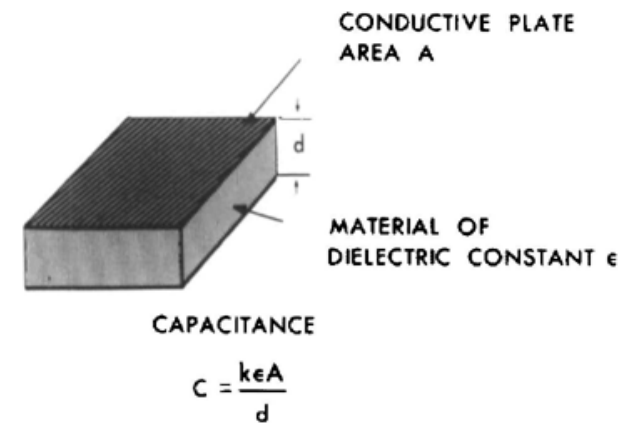

Figure 1. Diagram of simple parallel-plate capacitor. 
In the case of phospholipids, molecular breakdown is manifest in a temporary reversible increase in conductance. The increase may be caused by the release of ionizable protons from the polar-head groups of phospholipid molecules.

While normal resting potential exists between inside and outside surfaces of a membrane, the electric field within its lipid interior almost approximates the dielectric strength of lipids. Thus, in the resting state, the membrane insulation is on the verge of dielectric breakdown and breakdown may result if a stimulus of sufficient intensity is applied. If the dielectric strength of the membrane is reduced (e.g., by "foreign" molecules such as anaesthetics), a weaker stimulus can initiate dielectric breakdown, enhancing excitability of the membrane.

\section{THE Model}

The inside surfaces of two perforated metal plates were covered with lipids; the plates, separated by an impermeable insulating-mesh spacer, were clamped inside a small plexiglass chamber (Figure 2). Gas or vapour molecules were diffused into the lipid layer, changing its electrical

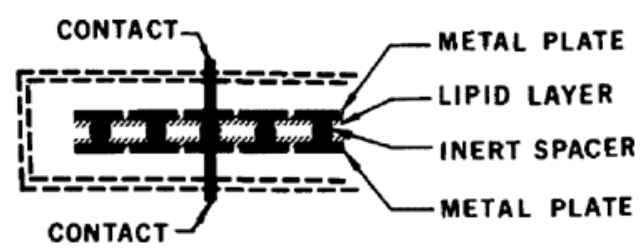

Figure 2. The model. Anaesthetic molecules in gas flowing through the chamber (----) diffuse through the holes in the metal plates into the lipid layer.

properties. Each of these changes in capacitance, conductance and dielectric strength was investigated independently. The exclusion of an aqueous phase ensured that any changes could be caused only by the molecules diffusing into the lipid.

The set-up used for most of the experiments is shown in Figure 3. Air, oxygen or other gases were metered through the system at a steady flow rate, controlled by needle valves and monitored by flowmeters previously calibrated for each gas. Anaesthetic vapours were added to the carrier gas from a bank of temperature-compensated vaporizers.

A heat-exchanger coil of copper tubing was interposed between the drier and the flowmeter to ensure identical temperature of all gases entering

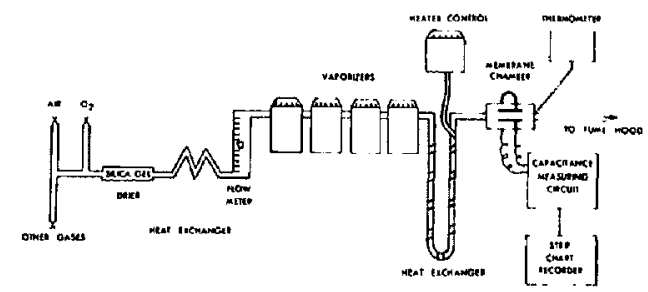

FIGURE 3. Experimental set-up.

the system. Another heat exchanger, wrapped with electrical heating tape, was used between the bank of vaporizers and the membrane chamber, to counteract cooling caused by vaporization. The temperature of gases entering the chamber was controlled by a variable transformer to which the heating tape was connected; it was monitored with a telethermometer with a sensor in the membrane chamber. The contacts of the membrane chamber were connected to the measuring circuit and the output was recorded on a strip-chart recorder.

\section{Materials and METhods}

Materials used to mimic the behaviour of the lipid interior of nerve membranes were olive oil, mineral oil, an aerosol of vegetable lecithin (PAM; Boyle-Midway, Toronto, Ont.) and mixtures of these, and a silastic membrane. Some experiments were repeated with egg lecithin $(99 \%$ pure), to eliminate the possibility that some changes might be due to impurities.

The lipid was applied to the plates with a cotton-tipped swab or by spraying. In most experiments, the lipid layers were thin, to reduce equilibration time. Because this atso reduced any changes in capacitance, some experiments were performed with lipid completely filling the space between the plates. It was found that change with complete filling could be calculated accurately from change with a thin layer. The results reported are as obtained with thin layers unless otherwise specified.

Dacron-reinforced silastic membrane (combined thickness $=0.15 \mathrm{~mm}$ ) of the type used in membrane oxygenators was found to be a satisfactory lipid analogue, ${ }^{8}$ with prolonged stability of its properties. It was cut slightly larger than the plate-size, to ensure complete coverage, and the spacer was omitted.

Experiments were performed at $24^{\circ} \mathrm{C} \pm 2^{\circ}$ with halothane, methoxyflurane (Penthrane), trichloroethylene (Trilene), enflurane, nitrous oxide, carbon dioxide, oxygen, nitrogen and hy- 
drogen at a flow-rate of 5 litres/min. At each stage, recording was continued until no further change was apparent.

During experiments with volatile agents, baseline was achieved with air flowing through the membrane chamber. The agent was added from a vaporizer, with stepwise increases and then decreases in concentration. Finally, the anaesthetic was turned off and steady state was re-established. This procedure was repeated with each agent.

With oxygen, nitrogen and hydrogen, baseline was established with helium flowing through the membrane chamber and then the helium was replaced with 100 per cent concentration of the study gas until no further change was recorded. After steady-state recording, the study gas was discontinued and helium reinstituted.

The procedure was slightly different for recordings of dielectric strength (q.v.).

Two additional sets of experiments were done. In the first, changes in capacitance were recorded during the introduction of several agents consecutively to determine the magnitude of their relative effect and to correlate findings with the minimal alveolar concentration (MAC) of the agents. In the second, combinations of anaesthetic agents were administered to determine effects upon capacitance and conductance.

The experiments were repeated for each property tested, first without lipid coating the plates and then with pure protein (serum albumin) between them.

\section{Capacisance}

Changes in capacitance were investigated with the apparatus shown in Figure 4A.

The membrane capacitor was made part of a monostable multivibrator ("single-shot") circuit which produced a rectangular pulse in response to each pulse from the generator (repetition rate $500 \mathrm{~Hz}$ ). The width of pulses produced by the circuit depended on the instantaneous capacitance of the membrane. These pulses were averaged, amplified, and shifted to a convenient basetine.

To eliminate errors caused by concurrent conductance changes, a thin insulating membrane, impermeable to anaesthetics, was interposed between the metal plates in addition to the spacer and the lipid film. As both the area of the metal plates and the distance between them were fixed, any changes in capacitance could be due only to changes in the dielectric constant of the material between the plates (Figure 1).

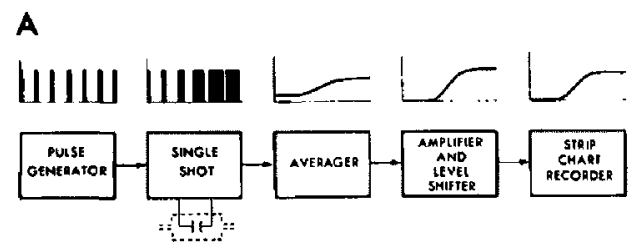

B

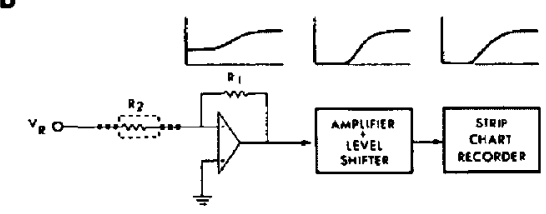

C

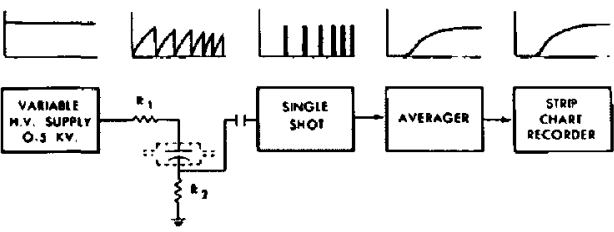

Figure 4. Apparatus for determining changes in capacitance (A), conductance (B), and dielectric strength (C). The upper traces represent agent-induced changes in signals at various points in the circuit.

Finally, changes in capacitance were recorded (Figure 4A).

\section{Conductance}

The effects on membrane conductance were investigated with the apparatus shown in Figure 4B. A reference voltage (VR) was connected to the input of an operational amplifier (A) the output voltage of which is given by $V_{O}=$ $-\left(R_{1} / R_{2}\right) V_{R}$. Assuming $R_{1}$ and $V_{R}$ are constant, $1 / R_{2}=K V o$. Thus the output of $A$ is directly proportional to the conductance of the membrane. This output was recorded continuously.

\section{Dielectric Strength}

Changes in dielectric strength during exposure to volatile agents, only, were investigated with the equipment shown in Figure $4 \mathrm{C}$.

The output of a variable high-voltage supply was connected through a high resistance to one plate of the membrane assembly. The other plate was grounded through a small resistance, so that each time the voltage exceeded the dielectric strength of the membrane the discharge was apparent as a voltage spike across that resistance. For each discharge, the "single-shot" generated a voltage pulse of fixed width and amplitude. 
These pulses were averaged, giving a voltage signal proportional to the membrane's rate of discharge. This was recorded on a strip-chart recorder.

With air flowing through the chamber at a constant rate, the high voltage was adjusted to slightly below the threshold value for discharge to occur. Anaesthetic was added from a calibrated vaporizer until no further change in the discharge rate was observed, and then was turned off. When the membrane had returned to equilibrium the experiment was repeated with a different concentration of the agent.

\section{RESULTS}

With all the agents tested, repetition of the experiments without the addition of lipid to the membrane, or with only protein between the plates, showed no significant effect (less than one per cent of changes observed with lipid) on capacitance, conductance, or dielectric strength.

The changes described below occurred with all the lipids tested and with the silastic membrane. Although the magnitude of change differed, the overall pattern of change was very similar.

\section{Capacitance}

Capacitance increased linearly, proportional to concentration, with all agents tested. Representative results obtained with halothane and enflurane are shown in Table $I$ and Figure 5. The

\section{TABLE I}

Comparison of Concentration of Halothane and Changes in Capacitance (Silastic Membrane)

\begin{tabular}{ccc}
\hline \multicolumn{2}{c}{$\begin{array}{c}\text { Halothane concentration } \\
\text { (per cent) }\end{array}$} & \\
\hline Dial setting & Actual value* & $\begin{array}{c}\text { Change in } \\
\text { capacitance }\end{array}$ \\
\hline 0 & 0.01 & 0 \\
0.5 & 0.5 & 9.0 \\
1.0 & 1.02 & 19.0 \\
1.5 & 1.57 & 29.5 \\
2.0 & 2.16 & 41.0 \\
2.5 & 2.54 & 49.0 \\
3.0 & 3.34 & 66.2 \\
2.5 & 2.55 & 50.0 \\
2.0 & 2.14 & 41.0 \\
1.5 & 1.55 & 29.3 \\
1.0 & 1.02 & 19.0 \\
0.5 & 0.51 & 9.5 \\
0 & 0.01 & 0
\end{tabular}

Capacitance change versus actual concentration: correlation coefficient $=1.000$

*Mass spectrometer (Searle, Medspect).

tChange was recorded in arbitrary units.

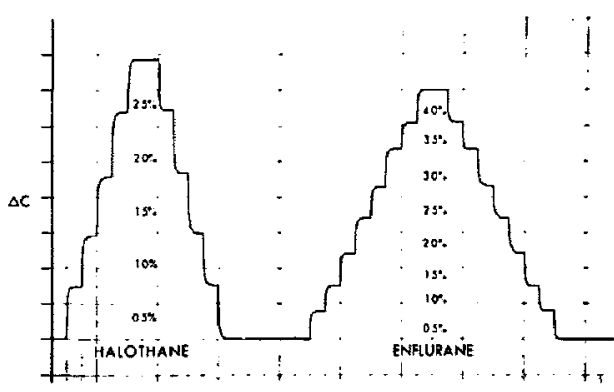

Figure 5. Changes in capacitance of the membrane induced by stepwise increase and decrease in concentration of halothane and enflurane. (The concentrations shown refer to the seltings on the vaporizer dial.)

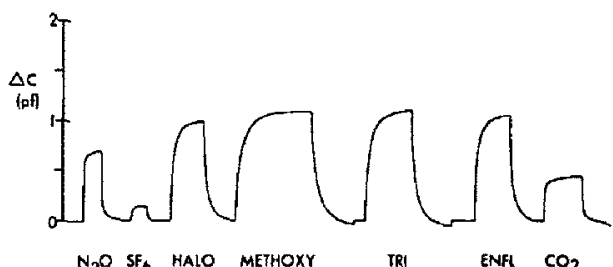

$\begin{array}{ccccccc}\mathrm{N}_{2} \mathrm{O} & \mathrm{SF}_{6} & \text { HALO } & \text { ME7HOXY } & \text { IRI } & \text { ENFI } & \mathrm{CO}_{2} \\ 100 \% & 100 \% & 1 \% & 0.2 \% & 0.2 \% & 2 \% & 100 \%\end{array}$

FIGURE 6. Comparison of changes in capacitance of the membrane induced by seven agents introduced consecutively. Baseline capacitance $=100 \mathrm{pf}$.

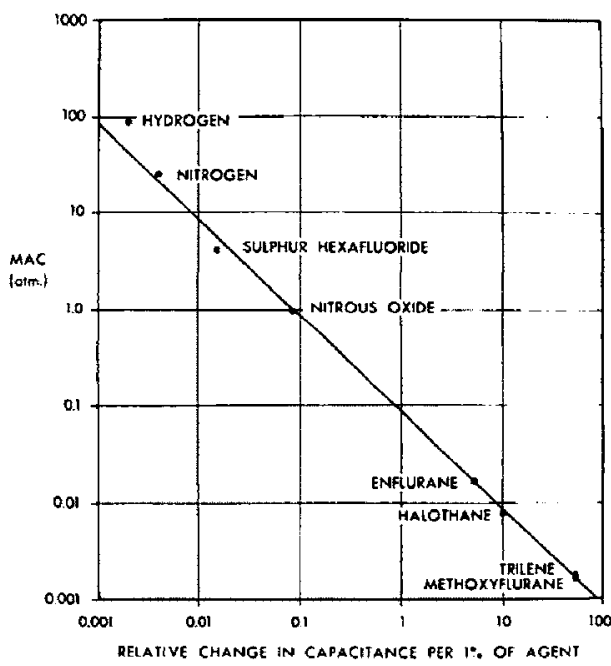

Figure 7. Comparison of the potency of anaesthetics and gases and their ability to alter capacitance of the membrane.

increase in capacitance was proportional to the potency of the agent (Figures $5,6,7$ ) and simultaneous administration of two or more inhalational anaesthetics had an additive effect (Figure 8). 


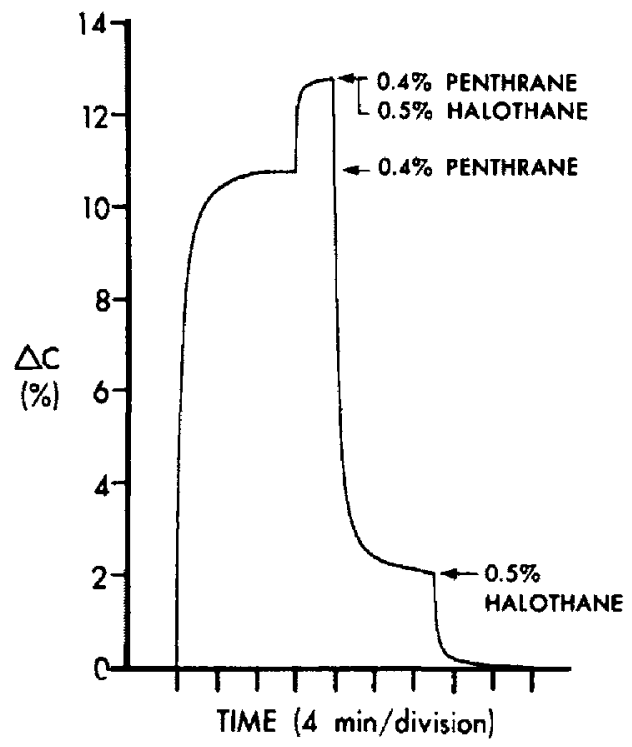

Figure 8. Changes in capacitance of the membrane when penthrane was introduced, halothane was added, and penthrane was discontinued, showing an additive effect during the period of simultaneous administration.

When the space between the plates was completely filled with lipids, the increase caused by the concentrations of agents corresponding to general anaesthesia (1.3 MAC) was approximately one per cent for olive oil and four per cent for the lecithins.

\section{Conductance}

The conductance of the model membrane increased linearly, proportional to concentration, with all the agents tested. The effect was additive (Figure 9).

The increase caused by the concentrations of agents corresponding to general anaesthesia (1.3 $\mathrm{MAC}$ ) was 12 per cent for the lecithins.

\section{Dielectric Strength}

All the volatile anaesthetic agents tested reduced the dielectric strength of the membrane. This reduction occurred with low concentrations and seemed fairly independent of higher ones (Figure 10).

\section{Discussion}

Nerve membranes contain a high proportion of phospholipids, and there is no reason to suspect that the bulk electrical properties of these and of the lipids in the model are different. Thus the

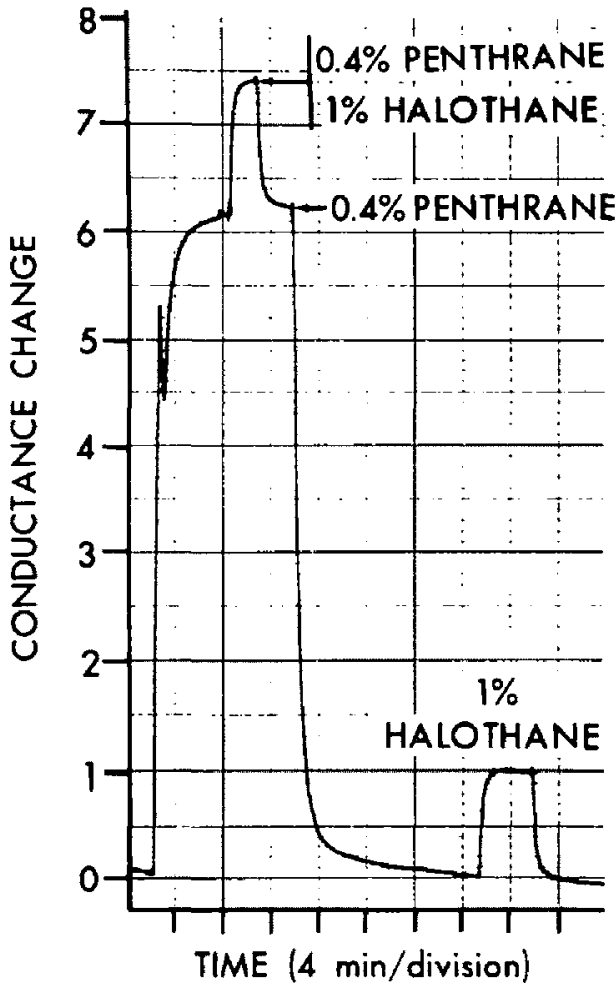

Figure 9. Changes in conductance of the membrane when penthrane and halothane were introduced separately and in combination, showing an additive effect.

PENTHRANE CONCENTRATION (\%)

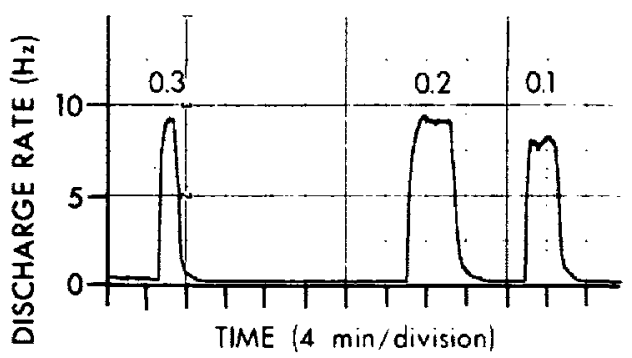

Figure 10. Changes in dielectric strength of the membrane with various concentrations of penthrane. Increase in the discharge rate indicates reduction in dielectric strength.

changes observed in the model can be expected to occur in real membranes also.

In the model, membrane thickness and area were fixed so that changes in capacitance were proportional to changes in dielectric constant. Real membranes, however, expand both in area ${ }^{9}$ 
TABLE II

Comparison of Correlation of Minimal alveolar Concentration (MaC) in Man with Otl Solubility and Relative Change in Capacitance in the Model Membrane

\begin{tabular}{|c|c|c|c|c|c|}
\hline Agent & $\begin{array}{l}\mathrm{MAC} \\
\text { (atm) }\end{array}$ & $\begin{array}{c}\text { OG } \\
\text { (oil-gas } \\
\text { partition } \\
\text { coefficient) }\end{array}$ & $\begin{array}{c}\Delta \mathrm{C} \\
\text { (relative change } \\
\text { in capacitance } \\
\text { per } 1 \% \text { ) }\end{array}$ & $M A C \times O G$ & $\mathrm{MAC} \times \Delta \mathrm{C}$ \\
\hline $\mathrm{N}_{2} \mathrm{O}$ & $1.01^{17}$ & $1.5^{9}$ & 1.4 & 1.52 & 1.43 \\
\hline Halothane & $0.0077^{17}$ & $224^{9}$ & 200 & 1.73 & 1.54 \\
\hline Methoxyflurane & $0.0016^{17}$ & $970^{9}$ & 1100 & 1.55 & 1.76 \\
\hline Trilene & $0.0017^{18}$ & $960^{9}$ & 1100 & 1.63 & 1.87 \\
\hline Enflurane & $0.0168^{19}$ & $98^{19}$ & 105 & 1.65 & 1.76 \\
\hline $\mathrm{SF}_{6}$ & $4.4^{17}$ & $0.258^{9}$ & 0.3 & 1.14 & 1.32 \\
\hline $\mathrm{N}_{2}$ & $24^{17}$ & $0.068^{9}$ & 0.068 & 1.63 & 1.63 \\
\hline $\mathrm{H}_{2}$ & $93^{17}$ & $0.05^{9}$ & 0.037 & 4.65 & 3.44 \\
\hline \multirow{3}{*}{\multicolumn{4}{|c|}{$\begin{array}{l}\text { Mean } \\
\text { S.D. }\end{array}$}} & 1.94 & 1.84 \\
\hline & & & & 1.11 & 0.67 \\
\hline & & & & $(57 \%)$ & $(36 \%)$ \\
\hline
\end{tabular}

and in thickness ${ }^{4}$ in the presence of anaesthetics, so that capacitance and dielectric constant are not then necessarily proportional. Therefore, consideration of anaesthetic effects must take into account both of these factors separately.

The observed increase in the effective dielectric constant of lipids caused by anaesthetic molecules, as indicated by increased capacitance of the model, was surprising. As the effective dielectric constant of a mixture of two substances is expected to lie between those of the constituents, one would expect the dielectric constant of a lipid to fall when an anaesthetic of a lower constant was added. The increase indicates that the structure of the lipid matrix was so altered as to allow the lipid molecules greater freedom to orient themselves in the electric field. This change has been described ${ }^{9,10}$ as a general "fluidization" or loosening of the membrane structure by anaesthetic molecules.

As the solubility of anaesthetic agents in human fat is approximately twice that in lecithin." changes in dialectric constant and conductance of human nerve membranes are presumably double those observed with lecithin in the model. This was not investigated.

Correlation between the change in capacitance and MAC (Table II and Figure 7) is even closer than between lipid solubility and MAC; it could be further improved by use of the proper mixture of lipids. The deviation of hydrogen and nitrogen from the line suggests that the reported MAC values for these may be erroneous. This may have resulted from the need for high pressures to attain anaesthesia with them, for at high pressure the reversal effect may lead to significant overestimation of the MAC.

Recent experiments with lipid membranes indicate that benzyl alcohol in low concentration $(7.5 \mu \mathrm{M}$ ) increases capacitance (see Figure 5 in Reference 4). Benzyl alcohol also reduces the dielectric strength of lipid membranes ${ }^{4}$ and of human and bovine erythrocyte membranes; ${ }^{12}$ however, the reported dependence of this reduction on concentration ${ }^{12}$ is questionable, as calculation of the results in the latter study was based on the assumption that thickness and dielectric constant are unaltered by benzyl alcohol. The present findings concur with reports that volatile anaesthetics reversibly increase membrane conductance in single, identifiable neurons ${ }^{2}$ and that alcohols, ${ }^{4,13}$ narcotics, ${ }^{14}$ and other anaesthetic agents ${ }^{15.16}$ increase the permeability of thin lipid membranes.

In the present study, changes occurred only when lipid or lipid analogue was present, and they were both of sufficient magnitude and in the proper direction to explain the effects of anaesthetic agents in vivo. Therefore, it is reasonable to conclude that anaesthesia is the direct result of changes in the passive electrical properties of membrane lipids.

The effect of anaesthetic molecules on nerve membranes can be summarized as initial transitory excitation caused by the decrease in dielectric strength of the membrane, followed by a stower sustained suppression induced by the increases in the membrane's dielectric constant and conductance. The decrease in excitability is a result of diminution in energy stored by the mem- 
brane capacitance and simultaneous increase in energy demand imposed on the ion pumps by increased conductance. In other words, of the total amount of energy supplied by the ion pumps, the proportion stored in the capacitor for the generation of action potentials diminishes, whereas the proportion that counteracts the enhanced leakage increases. When a certain volume occupation of foreign molecules in the cell mem. brane is reached, generation and propagation of action potentials becomes impossible and the cell is said to be anaesthetized.

Whether a membrane becomes excited, narcotized, or remains unaltered in response to anaesthetic molecules depends on the relative magnitude of the opposing changes. This hypothesis could explain the full spectrum of states of excitability that may exist in a single nerve membrane. Indeed, the pre-narcotic excitability exhibited by single identifiable neurons, ${ }^{2}$ which is extremely difficult to reconcile with existing theories of anaesthesia, poses no problem with the hypothesis proposed here.

\section{SUMMARY}

Changes induced by inhalational anaesthetic agents were investigated in a simple membrane model. All the agents tested increased the membrane's electrical capicitance and conductance linearly, proportional to concentration and potency, and decreased its dialectric strength independently of concentration. When protein was substituted for lipid, the same agents had no significant effect on capacitance, conductance, or dielectric strength.

Based on these findings, the following hypothesis is presented. Anaesthetic agents exert their influence on the lipid portion of nerve membranes. They enhance excitability by reducing the dielectric strength of the membrane and depress excitability by increasing the membrane's dielectric constant and passive conductance. The degree of excitability or narcosis at any instant depends upon the relative magnitude of these opposing effects.

\section{RÉSUMÉ}

Nous avons fait l'étude des modifications produites par les anesthésiques d'inhalation sur un modèle de membrane. Tous les agents étudiés élevaient de façon linéaire, de façon proportionnelle à leur concentration et à leur puissance, la conductance et la capacitance électrique de la membrane. Ils diminuaient sa rigidité diélectrique indépendamment de la concentration utilisée.

Si l'on substituait aux couches lipidiques internes de notre modèle une couche protéinique. les mêmes anesthésiques n'avaient plus d'effets significatifs sur la capacitance, la conductance et la rigidité diélectrique.

A partir de ces faits, l'hypothèse suivante est émise : les anesthésiques exercent leur action sur la portion lipidique de la membrane cellulaire. Ils augmentent l'excitabilité cellulaire en diminuant la rigidité diélectrique de la membrane, et ils exercent une action dépressive en augmentant sa constance diélectrique et sa conductance passive.

Le degré d'excitabilité ou de narcose à un instant donné est fonction de l'importance relative de ces effets opposés.

\section{ACKNOWLEDGEMENTS}

The author is grateful to Dr. D.J. Steward for his continued encouragement, to Dr. Philip Seeman, Dr. Joan Boggs, and Dr. Alison Froese for their helpful criticism of the report, and to the Medical Publications Department, Hospital for Sick Children, Toronto, for assistance in preparing this manuscript.

\section{REFERENCES}

1. Armstrong, C.M. \& Binstock, L. The effects of several alcohols on the properties of the squid giant axon. J. Gen. Physiol. 48: 265 (1964).

2. Chalazonitis, N. Effects of anesthetics on neural mechanisms. Selective actions of volatile anesthetics on synaptic transmission and autorhythmicity in single identifiable neurons. Anesthesiology 28:111 (1967).

3. White, S.H. \& Thompson, T.E. Capacitance. area, and thickness variations in thin lipid films. Biochim. Biophys. Acta 323: 7 (1973).

4. Ashcroft, R.G., Coster, H.G.L., \& SMITH, J.R. The molecular organisation of bi-molecular lipid membranes. The effect of benzyl alcohol on the structure. Biochim. Biophys. Acta 469: 13 (1977).

5. Benz, R., Frölich, O., LäUger, P., \& Montal. M. Electrical capacity of black lipid films and of lipid bilayers made from monolayers. Biochim. Biophys. Acta $394: 323$ (1975).

6. Lauger, P., Lesslauer, W., Marti, E., \& RichTER, J. Electrical properties of bimolecular phospholipid membranes. Biochim. Biophys. Acta 135: $20(1967)$.

7. WHITE, S.H. Thickness changes in lipid bilayer membranes. Biochim. Biophys. Acta 196: 354 (1970).

8. White, D.C., WARDLEY-SMITH, B.. \& Halsey, M.J. Elastomers as analogues of anaesthetic receptors. Brit. J. Anaesth. 44: 1020 (1972). 
9. SeEman, P. The membrane actions of anesthetics and tranquillizers. Pharmacol. Rev. 24(4): 583 (1972).

10. Ueda, I., Smith, D.D. \& Eyring, H. Anesthetic interaction with a model cell membrane: expansion, phase transition, and melting of the lecithin monolayer. Anesthesiology 4I: 217 (1974).

11. LowE, H.J. Dose-regulated penthrane (methoxylurane) ane sthesia. North Chicago, Ill., Abbott Laboratories (1972).

12. Pilwat, G., Zimmerman, U., \& Riemann, F. Dielectric breakdown measurements of human and bovine erythrocyte membranes using benzyl alcohol as a probe molecule. Biochim. Biophys. Acta 406: 424 (1975).

13. Gutknecht, J. \& Tosteson, D.C. Ionic permeability of thin lipid membranes. Effects of $\mathrm{N}$-alkyl alcohols, polyvalent cations, and a secondary amine. J. Gen. Physiol. 55: 359 (1970).

14. Bangham, A.D., Standish, M.M., \& Miller, N.
Cation permeability of phospholipid model membranes: effect of narcotics. Nature 208: 1295 (I965).

15. Johnson, S.M. \& Bangham, A.D. The action of anaesthetics on phospholipid membranes. Biochim. Biophys. Acta 193: 92 (1969).

16. Johnson, S.M., Miller, K.W., \& Bangham, A.D. The opposing effects of pressure and general anaesthetics on the cation permeability of liposomes of varying lipid composition. Biochim. Biophys. Acta 307; 42 (1973).

17. Miller, K.W., Paton, W.D.M., Smith, E.B., \& Smith, R.A. Physicochemical approaches to the mode of action of general anesthetics. Anesthesiology 36: 339 (1972).

18. Tremblay, N.A.G. Department of Anaesthesia, Ste-Justine Hospital, Montreal. Personal communication (1977).

19. Eger, E.I., II. Anesthetic uptake and action. Baltimore, MD., Williams \& Wilkins (1974). 